\title{
A Espanha de Pierre Monbeig e o primeiro esboço do modelo das franjas pioneiras (1930-1935)
}

Um geógrafo face à mundialização

The Spain of Pierre Monbeig and the first draft of pioneer fringe (1930-1935): A

Geographer in the face of globalization

La España de Pierre Monbeig y el primer borrador del modelo de frentes pioneros (1930-1935): un geógrafo ante la mundialización

L'Espagne de Pierre Monbeig et la première ébauche du modèle des franges pionnières (1930-1935) : un géographe face à la mondialisation

\section{Larissa Alves de Lira}

\section{OpenEdition}

Journals

\section{Edição electrónica}

URL: https://journals.openedition.org/terrabrasilis/1465

DOI: $10.4000 /$ terrabrasilis. 1465

ISSN: 2316-7793

\section{Editora}

Rede Brasileira de História da Geografia e Geografia Histórica

\section{Refêrencia eletrónica}

Larissa Alves de Lira, «A Espanha de Pierre Monbeig e o primeiro esboço do modelo das franjas pioneiras (1930-1935)», Terra Brasilis [Online], 5 | 2015, posto online no dia 01 julho 2012, consultado o 05 dezembro 2022. URL: http://journals.openedition.org/terrabrasilis/1465 ; DOI: https://doi.org/ 10.4000/terrabrasilis. 1465

Este documento foi criado de forma automática no dia 5 dezembro 2022.

All rights reserved 


\section{A Espanha de Pierre Monbeig e o primeiro esboço do modelo das franjas pioneiras (1930-1935)}

Um geógrafo face à mundialização

The Spain of Pierre Monbeig and the first draft of pioneer fringe (1930-1935): A Geographer in the face of globalization

La España de Pierre Monbeig y el primer borrador del modelo de frentes pioneros (1930-1935): un geógrafo ante la mundialización

L'Espagne de Pierre Monbeig et la première ébauche du modèle des franges pionnières (1930-1935) : un géographe face à la mondialisation

Larissa Alves de Lira

\section{Introdução}

1 Em 1911, o geógrafo Jean Brunhes ${ }^{1}$ escrevera um esboço de uma geografia humana das ilhas Baleares publicado na Revue des deux mondes. 0 artigo referia-se a duas belas ilhas, Maiorca e Minorca. A maior, Maiorca, possuía uma capital, Palma, disposta em anfiteatro sobre uma colina leve. A ilha era cercada ao sul e ao norte por duas cadeias de montanhas paralelas, cujo centro era mal explorado, os portos se distanciavam das cidades e seus habitantes, com ajuda de animais, empurravam carroças. Plantadores, pastores e pescadores trabalhavam juntos em suas laboriosas atividades diárias dessa vida mediterrânea. Sua descrição mostrava ao mundo hábitos exóticos de gêneros de vida resistentes ao tempo em pleno século XX. Já em 1932, o jovem geógrafo Pierre Monbeig² (1908-1987) publica um outro artigo sobre as ilhas Baleares, que é fruto de sua primeira opção temática para construir uma tese de doutorado. Palco de uma luta política intensa, as Baleares eram cenário de aplicação de distintas doutrinas econômicas, à partir das quais os seus governantes se empenhavam em modernizar os mercados e as rotas, sanear planícies alagadas, inserir novas culturas, modernizar o 
emprego de técnicas agrícolas e exportar a produção em direção à Itália. Isso nos arredores do... século XVIII!

2 O que acontecera na geografia francesa entre 1911 e 1932 que possibilitou o aparecimento de abordagens tão distintas, como essas representadas por Jean Brunhes e Pierre Monbeig para o caso das ilhas Baleares? O escopo deste artigo consiste em compreender como o jovem estudante Pierre Monbeig, recém diplomado pela Licence e pela Agrégation em História e Geografia, decidiu pelo caminho da pesquisa em Geografia Humana da Espanha como tema de tese de doutoramento. Consequentemente, caberia indagar, em primeiro lugar, se os geógrafos dessa geração, sendo ele um pesquisador dentro desse conjunto, estariam desde já inseridos em um processo de internacionalização da geografia francesa e de atualização de seus referenciais teóricos com o intuito de compreender os processos modernos. A partir deste objeto, somos levados a questionar se na Espanha de Pierre Monbeig já havia um primeiro esboço do modelo das franjas pioneiras e da colonização moderna dos novos espaços coloniais.

Respostas a estas questões serão esboçadas à luz de uma história intelectual que busca múltiplos cenários na definição dos projetos acadêmicos, revelando aspectos controversos e compósitos, das opções individuais, mas também de uma geração e de seu contexto. Há ainda outro aspecto metodológico essencial deste trabalho: estamos atentos à trajetória de Pierre Monbeig num movimento em que as rupturas são enquadradas no interior de uma lenta história intelectual. Para nós, o peso das heranças é significativo e a escolha da periodização que ultrapassa os habituais momentos de ruptura, como será a ida de Pierre Monbeig ao Brasil, coloca, a despeito de uma curta conjuntura, uma outra ordem de problemas, suscitadas a partir do pressuposto da diluição das grandes viradas em trajetórias intelectuais.

4 Inserido nos projetos de uma geração, ele seguramente agiu sob os impulsos do contexto. Nesse sentido, a articulação da Geografia com uma diplomacia cultural nascente ainda pode ser enfocada, bem como a possibilidade de se traçar um outro horizonte histórico que permearia a geografia francesa, no qual a sua atuação internacional esteja em foco, concorrendo com outros programas científicos. Em resumo, um momento de seduções, mas também de lutas, estratégias, articulações e tomadas de posição em âmbito internacional deve ser traçado se se quiser compreender como um jovem de postura militante e em processo de definição da sua carreira, determina seus propósitos e estratégias em função do contexto científico, mas também político, e quais foram as principais características desta proposta intelectual.

5 Argumentaremos que a escolha de Pierre Monbeig pela Geografia Humana e pela Espanha se dá por uma gama de impulsos: em primeiro lugar, tem-se como cenário a própria sedução que as terras do Sul da França, semelhantes às espanholas pela originalidade do quadro mediterrâneo, exerceram sobre um jovem vindo do norte do país. Ademais, a Geografia Humana representava para Monbeig uma ferramenta de reflexão e engajamento nos problemas do mundo contemporâneo. Esta característica se aprofunda neste momento, sendo os conflitos espanhóis um motivo de ativismo de Monbeig. De outro lado, um dever patriótico no que diz respeito à França, na tentativa consolidar novos mercados, após um momento de crise, induz este geógrafo ao estrangeiro. Arrault traças as principais características da consciência da interdependência internacional que marca este período:

(...) si l'on se contente de définir la mondialisation à partir de critères économiques tels que le commerce extérieur ou les investissements à l'étranger. Mais si l'on 
cherche à définir plus spécifiquement la mondialisation comme un processus de mise en relation et surtout de mise en dépendance des parties du monde entre elles, comme une dynamique de rupture d'isolement on ne voit pas a priori en quoi l'internationalisation des économies produirait plus de mondialité (dimension mondiale des phénomènes) qu'une crise économique d'échelle mondiale (Arrault, 2007 : 493-494).

6 Há uma efervescência de trabalhos e teses sobre diversas partes do mundo no seio do Instituto de Geografia. Trata-se de um contexto de internacionalização que agita a Geografia francesa e que passa a estimular temáticas sócio-espaciais em âmbitos de concorrência de interpretações: os países de colonização recente, chamados de "pays neufs", são elegidos como peças chaves da compreensão francesa dos processos de mundialização. ${ }^{3}$ Uma ilha espanhola é entendida como uma espécie de país novo, expressando uma postura de Monbeig de, através de sua escolha temática, colocar-se no centro dessas renovações.

\section{0 encanto pelo Mediterrâneo}

7 Nascido em Marissel, no norte da França, Pierre Monbeig passara toda a infância em Paris, cerceado pelo conflito bélico, que é declarado quando ele tinha 6 anos. Mesmo que de origem familiar "béarnais", ele só conhecera o sul da França aos 15 anos de idade, o que foi para ele uma revelação. Béarn era uma pequena região histórica do Midi-aquitain, no Sudoeste da França, no seio dos Pirineus atlânticos, mas vizinha do Mediterrâneo. Esta região é marcada por belas paisagens naturais e por uma rica história, cuja presença de pequenos Estados feudais e guerreiros deram suporte à política de Henrique IV (Vidal de la Blache, 1994: 515).

8 Os geógrafos de tradição francesa são atraídos pelo Mediterrâneo. A tradição remonta a Malte-Brun, Elisée Reclus e a Vidal de la Blache ${ }^{4}$ (Deprest, 2002) e segue nas figuras de discípulos vidalianos que se dedicaram à região. Jules Sion e Max Sorre foram os autores que substituíram Jean Brunhes no volume sobre o Mediterrâneo da Geografia Universal e cuja publicação se deu em 1934. Vidal de la Blache registrou a sua admiração pelas margens do Midi: "Sans doute la nature se montre douce et clémente dans ces parties abritées par l'écran de montagnes, qui ressemble à des corbeilles de fleurs penchées au bors de flots" (Vidal de la Blache, citado por Claval, $1988: 386$ ). Jules Sion atesta o quanto a região do Sul da França era original em relação a todas as outras paisagens francesas: "Il n'y a guère en France de région naturelle dont l'individualité soit aussi saisissant que la bordure de la Méditerrânée" (Sion, 1934).

9 Além da admiração pelo Sul, região de cruzamento da França com a Espanha, se o testemunho de Monbeig anuncia, de um lado, a possibilidade que estava dada aos estudantes para escolherem o tema da tese, é evidente, em contrapartida, que sua escolha não fora feita sem o aval do mestre. Albert Demangeon, por sua vez, também era bastante seduzido pelo Midi: “aucune région du globe n'offre à la description géographique plus de séduction que le pays de la Méditerranée" (Demangeon, 1937: 307). Para Clout,

Demangeon encouraged him to think about undertaking further research for a state doctorate (doctorat d'état) necessitating many years of preparation. Master and pupil discussed Pierre's teenage fascination with the Mediterranean world and agreed that a study of the human geography of the Balearic Islands would be an appropriate topic for a major thesis (Clout, 2013: 56). 
10 A sedução pelo Mediterrâneo se acentua após o conflito bélico. 0 mar interior dos geógrafos franceses estava envolto por uma nova sensibilidade que aflora na sociedade europeia, que encanta e permeia os espíritos. Para Basfao, no começo do século XX, o Mediterrâneo representava a paixão, o idealismo e a compensação cultural à realidade tecnocrática que rondava os impulsos econômicos (Basfao, 1991: 46). Um feitiço mediterrâneo sobre um jovem que respira os ares de um idealismo cultural europeu.

\section{As ebulições políticas da Espanha}

11 Este jovem pesquisador é igualmente engajado nas oportunidades práticas de intervenção na economia e na questão do urbanismo, que impulsionam os geógrafos à ação (Robic, 1996b). Sua vinculação às questões contemporâneas e às influências do contexto político é indubitável. Segundo Ferras, as agitações políticas da Espanha tiveram importante papel nas suas escolhas: “L'ouvre espagnole de Pierre Monbeig se situe au début des années 1930; on sait quelle coupure cette période représente dans l'histoire, la géographie, l'évolution sociale et économique du pays" (Ferras, 1991: 68). Comentando a indagação de Claude Bataillon sobre o porquê de escolher a Espanha e não a Itália, Pierre Monbeig deixa transparecer a importância do critério político: "Ah! Non pas l'Italie. Je détestais les italiens à cause de Mussolini (mais cela nous entraînerait trop loin) (...)" (Monbeig in Bataillon, 1991: 29). Desse modo, o idealismo artístico da cultura mediterrânea conjuga-se com um idealismo político.

O próprio Monbeig dá vazão à intenção de cooperar diretamente com a solução dos problemas espanhóis, para os quais suas pesquisas poderiam auxiliar em uma reflexão voltada para as tarefas práticas. O principal problema espanhol, a seus olhos, consistia na ausência de democratização do acesso à terra: "nous voudrions, en utilisant les études fragmentaire publiées dans les années dernières de parte et d'autre des Pyrénées, essayer de dégager les causes du problème agraire, de distinguer les divers aspects et d'indiquer les remèdes qui sont actuellement mis en ouvre" (Monbeig, 1991: 75).

13 Em 1930, a Espanha enche-se de esperança: a ditadura de Primo de Rivera chega ao fim, Alphonse XIII deixa o país e a República é instaurada em 14 de abril de 1931 (Ferras, 1991: 68). A liderança do movimento é encabeçada pelos ministros Alcala Zamora e Azána, além de outros companheiros, e suas propostas incidem sob diversos problemas espanhóis: reestruturar o exército, organizar em novas bases as relações entre a Igreja e o Estado, satisfazer as aspirações catalãs sem romper com a unidade espanhola e, por fim, promover melhoras no regime agrário (Monbeig, 1991: 74-75). Reformas estruturais do Estado são aguardadas, principalmente aquelas que diziam respeito à Reforma Agrária. As opiniões de Pierre Monbeig sobre este assunto estão profundamente envolvidas num engajamento contra a oligarquia latifundiária. Surpreendentemente, a publicação de seu artigo se dá um pouco antes que a Reforma Agrária tenha sido realmente implementada (1932), ou seja, seu trabalho é também um esforço de convencimento e propaganda.

14 Tanto no estudo do passado quanto no do presente, a base da política econômica defendida por ele é o de uma modernização do território promovida pelo Estado com suporte popular. O Estado seria um equalizador entre os grupos de pressão, permitindo uma ação econômica que favorecesse a grande e a pequena propriedade, e que 
imprimisse um esforço para equalizar a distribuição da riqueza. No que toca este ponto, Pierre Monbeig revela sua posição: "la loi indique très justement que la coopération et l'exploitation collective devront être préférées à la possession individuelle (...)" [grifos nossos] (Monbeig, 1991: 78). Uma posição ideológica que não se radicaliza em direção à abolição da propriedade, saúda, contudo, a intervenção coletiva e o controle estatal, ao qual ele nomeia "un socialisme de droite, pour reprendre les termes de notre topographie parlamentaire, un socialisme réformiste" (Monbeig, 1991: 79).

\section{A necessidade de contribuir na recuperação da economia francesa através das relações econômicas da França com o estrangeiro}

15 Após a crise de 1929, numa época de surgimento de problemas comuns em âmbito mundial, o contexto econômico francês impulsiona a sociedade a resolver questões de política externa. Adepto de uma geografia que possa contribuir com as tarefas práticas das nações, Pierre Monbeig também define seu objeto de pesquisa em função dos interesses econômicos da França. Se a Espanha mobiliza sua militância política, a França traz à cena seu sentimento patriótico, concorrendo na definição das temáticas e da abordagem das pesquisas. A geografia francesa não escapou desse liame de interesses.

A questão demográfica é um dos mais graves problemas franceses. Após 1918, e durante um período de 25 anos, o crescimento demográfico francês foi de apenas 1,2 \% (Fohlen, 1985: 81). Tendo perdido um saldo de vidas na ordem 1,4 milhões, o que representou uma extinção de 10,5 \% da população ativa, frente a uma perde da 9,8 \% na Alemanha, 6,2 \% na Itália e 5,1 \% na Inglaterra (Fohlen, 1985: 81), esta difícil situação era maquiada pela chegada de estrangeiros. Porém, este fluxo diminuiu a partir de 1931 devido a grande depressão. 0 governo chegou a proibir abortos e uso de contraceptivos em 1920 (Fohlen, 1985: 82). É por isso que as correntes populacionais espanholas interessam a Pierre Monbeig. Efetivamente, ele publica um artigo sobre a Espanha versando exatamente sobre este tema. Segundo ele, tal país representa o principal fluxo migratório continental europeu para França, alçando ao âmbito dos interesses franceses a importância do estudo econômico da Espanha.

o desafio do governo francês, segundo Monbeig, é o aprimoramento dos mecanismos de atração da economia francesa (que não vê com bons olhos a emigração da sua população) e que oscila: "ces rapports annuels du Ministerio del Trabajo montrent que l'exode des Espagnols, interrompu par la Guerre, retorouve son actitivité" (Monbeig, 1991: 201). Ele também versa sobre uma contribuição às políticas de melhoria das condições de trabalho do operário espanhol na França. Pierre Monbeig reconhece o interesse francês na atração da população espanhola. Segundo ele, há um conflito que envolve ambas as nações: "les inspecteurs du Ministerio del Trabajo se paignent des efforts du gouvernement français pour encourager et faciliter les naturalisations (Monbeig, 1991: 201). E ainda, os trabalhadores espanhóis são muitas vezes maltratados pelos patrões franceses, e o governo espanhol esbraveja. Para ambos os problemas, ele assevera que seria necessário melhorar as condições políticas e econômicas da Espanha, acrescentando que uma possível solução para a crise migratória seria a melhoria da recepção francesa: "il convient donc, pour compléter la législation, de mieux recevoir le 
journalier espagnol et perfectionner sa technique" (Monbeig, 1991: 201). A análise geográfica poderia contribuir na resolução desses conflitos internacionais.

\section{A participação de Pierre Monbeig e da geografia francesa na política cultural da França na década de 1930}

Para contribuir com a solução destes problemas econômicos, a diplomacia elege a política cultural voltada ao mundo latino como uma área de ávido interesse. ${ }^{5}$ As inciativas de propaganda chegam a anteceder a Terceira República, com a fundação da École Française d'Athènes em 1846. A ela sucede a École de Rome (1873). Em 1928 é fundada a École de Madrid (Gran-Aymerrich e Gran-Aymerrich, 1991: 175) da qual Pierre Monbeig fará parte e que proporcionará suporte institucional aos seus trabalhos doutorais, antes de partir para o Brasil.

19 A fundação da escola de Atenas está associada, entre outros objetivos, ao intuito de garantir a influência francesa na Grécia, logo após as lutas de independência, e fazer face à influência inglesa e prussiana ${ }^{6}$ em Madrid (Gran-Aymerrich e Gran-Aymerrich, 1991). Nesse sentido, uma das primeiras ações de política cultural francesa no estrangeiro se dá no Mediterrâneo: " "La Casa Velazquez est implantée à Madrid dans un esprit tout à fait semblable, pour compléter l'action scientifique française en Médditerranée face à la science allemande" (Gran-Aymerrich e Gran-Aymerrich, 1991: 175). No que concerne à Espanha, a inciativa de criar um instituto que se unisse as missões das escolas de Roma e de Atenas foi confiada a P. Paris e G. Radet e está inserida em um contexto de maior intensificação da concorrência no interior do mundo científico:

Cependant, l'imminence du conflit mondial et la nécessité politique de gagner l'Espagne à la France entraînent l'Institut français de Madrid dans une lutte ouverte avec les représentants de l'Allemagne dans la péninsule Ibérique (Lantier 1916). La concurrence scientifique des deux puissances continentales participe d'une âpre rivalité d'influence (...) (Gran-Aymerrich e Gran-Aymerrich, 1991: 183-184).

21 Avessa a todo tipo de propaganda política ou econômica, reticente em relação a um discurso expansionista, a Terceira República (1870-1940) abre exceção para a propaganda no estrangeiro de caráter cultural (Suppo, 2000: 311-312). Nas palavras de Suppo, "a França será o primeiro país a propor como estratégia de dominação colonialista do ensino do francês a partir da criação, em 1883, da Aliança Francesa. 'Todo cliente da língua francesa é um cliente natural dos produtos franceses' era o lema que orientava suas ações" (Suppo, 2000: 312). A cultura francesa é vista como estímulo de consumo de produtos culturais (livros, teatros, ópera, vinhos etc.) e a propaganda é realizada diretamente pelo governo (Suppo, 2000: 313).

É justamente a Espanha um dos principais alvos da política de propaganda francesa na década de 30. No mês de Novembro de 1928 foi inaugurada a École Française de Madrid, chamada Casa de Velázquez, onde Pierre Monbeig fará seus estudos de espanhol e terá apoio para realizar os trabalhos de campo. As origens do Instituto de estudos hispânicos se reportam a 1913, data de fundação do centro de estudos franco-espanhol. Esses institutos lograram construir um discurso de unidade franco-espanhol de liderança francesa. 
23 Nas palavras dos fundadores da Escola de Madrid, a França cumpre um importante papel na difusão da cultura espanhola: para esses conferencistas, através da cultura francesa se encontraria a alma espanhola, onde está subentendido que a França poderia reunir um conjunto de transferências culturais e destacar as singularidades nacionais, devido à sua posição de centralidade da cultura mediterrânea: "L'élément imanente du génie espagnol dans la culture occidentale sera mis en valeur s'il réussit à s'accorder en une polyphonie parfaite avec les notes vibrantes qui fait entendre la France immortelle dans le concert de la civilisation latine" [grifos nossos] (Oliveros apud Université de Paris, 1929, p. 268). Em alguns momentos, a intervenção do diretor do ensino superior da Espanha exprime a importância da cultura francesa para os espanhóis no tom de uma dívida profunda. Este é o discurso divulgado no Livret de l'étudiant da Sorbonne, e, logo, um discurso de recepção dos novos estudantes e orientação às atividades do instituto:

Nous aurons tout profit à renouvelés notre dette envers vous, illustres professeurs de la Sorbonne. Le mouvement actuel de la pensée et de la science française, peutêtre pour nous un des meilleurs moyens de mettre mieux en lumière l'essence profonde de l'Espagne, les élans originaux de l'âme espagnole, toujours rebelle à des constatations purement conceptuelles, retrouvant grâce à vous leur légitimé. Grâce à vous, l'Espagne peut rétablir sa confiance en elle-même et redresser ses énergies affaiblies ou détournées de leurs véritable sens. L'esprit national désorienté est revenu désormais sur son chemin. » (Université de Paris, 1929: 268).

$24 \mathrm{Na}$ Casa de Velásquez, Pierre Monbeig compõe um círculo de amigos hispanistas, geógrafos, artistas e historiadores. Entre eles, Pierre Vilar, que direcionará sua tese posteriormente à história. $\mathrm{O}$ acolhimento na instituição possibilitava trabalhos de campo e viagens coletivas:

C'est donc, dans une Espagne troublée que les pensionnaires artistes et scientifiques de l'année universitaire 1930-1931 prirent place: parmi eux, Pierre Vilar, élève, comme Monbeig, d'Albert Demangeon. Il avait déjà effectué une reconnaissance studieuse à Barcelone, en 1927, en vue d'étudier les particularités catalanes, à travers la géographie industrielle de la région, ainsi que l'impact économique et social de l'électrification de l'Èbre et de ses affluents. Très bien reçu par Legendre, quelques jours après les événements de Jaca, il s'en fut, en sa compagnie, avec le ménage Monbeig et Gabrielle Berrogain, passer Noël à La Alberca, dans les Hurdes (Delaunay, 1994: 256).

25 A vinculação de Pierre Monbeig com a Espanha se deu em um momento em que as políticas de propaganda se intensificavam em relação a este outro país latino, um pouco antes da crise de 1929. Mais amplamente, a disciplina geográfica como um todo sob liderança de Emmanuel De Martonne e Albert Demangeon, é parte ativa nas atividades do Instituto. Na lista de cursos especiais proferidos pelos professores da Sorbonne, Emmanuel De Martonne figura com um curso de iniciação à geografia, com enfoque especial sobre a geografia regional da Espanha (Université de Paris, 1935: 139), além do quadro de lições especiais em que figura a participação de Pierre Monbeig, demonstrando com isso seu engajamento às atividades pedagógicas do instituto:

Les cours spéciaux 1933-1934 ont été les suivants: Art : M. R. Schneider : Du nouveau sur l'art espagnol; Histoire: M. A. Viñas: les Grandes Étapes de l'histoire d'Espagne ; le Reconquête ; Littérature : M. P. Salina : la Vie andalouse das les toman contemporain; Musique: M. H. Collet: La musique espangole au sezième siècle ; Linguistique: M. R. Lapesa: Questions de linguistique du moyen âge; Geógragraphie: M. Monbeig: Madrid; Législation : M. d'Ardenne de Tizac: Explication de la nouvelle condifiction dans les Fueros d'Aragon. (Université de Paris, 1935: 140) 
Nesse período, um professor de Monbeig na Sorbonne, Emmanuel de Martonne, atuou como um "tecedor de redes internacionais" da geografia francesa, ${ }^{8}$ seja através de institutos como este, seja através de outras organizações, seguindo as palavras de Delfosse (2001). As missões na Alemanha (1898), nos Estados Unidos (1917) e na Romênia (1922) marcam um momento de virada da geografia francesa: "certes les géographes français peuvent apprendre des méthodes d'enseignement de la géographie en Amérique, mais ce qui est nouveau, c'est que les géographes français peuvent, selon la formule de De Martonne, rendre des services" (Delfosse, 2001: 191-192). Quando Emmanuel de Martonne torna-se secretário geral da União Geográfica Internacional após o congresso de Paris de 1931 ele empreenderá uma estratégia de internacionalização que não prescinde das áreas latinas:

D'un autre côté, le directeur de l'Institut de géographie, invité à donner une série de conférences à l'Université de Buenos-Aires, a visité, outre la République Argentine, le Brésil où il a pris la parole devant l'Académie des Sciences et la Société de Géographie de Rio de Janeiro, le Chili où il a fait trois conférences à l'Université de Santiago, et a même, grâce à une journée de vol d'Antofagasta à Lima, pour faire connaître un peu la géographie française dans la capitale du Pérou (De Martonne, 1934: 277).

Deve-se levar em conta a problemática que estava envolvida nesse novo esforço. Por falta de financiamento, as terras em regiões estrangeiras tinham mais dificuldade de serem estudadas, uma vez que para muitos era indispensável o trabalho de campo. Dessa forma, para que tais teses fossem empreendidas, era necessário o desenvolvimento de instituições preparadas a lhes dar suporte. É esse o mais importante argumento que favorece a associação da geografia francesa não apenas com a União Geográfica Internacional, mas também com a diplomacia cultural. Essa política cultural elegera a Espanha como seu espaço de ação na década em que Pierre Monbeig começa seus estudos de tese e ele não prescinde dessa política de propaganda da cultura francesa.

\section{A abertura da geografia francesa ao mundo: uma vocação universalista}

Assim, a geografia francesa empenhava-se em definir suas áreas de influência em contexto de concorrência entre as diversas escolas. O congresso internacional de geografia, ocorrido em Paris em 1931, sugerira o estudo dos "pays neufs" no seio da Geografia Humana (Gallois, 1931). Mas isto também não significava um descolamento do que já havia sido praticado no Instituto de Geografia da Sorbonne. O trabalho de Pierre Monbeig sobre a Espanha não se desloca da tendência das monografias regionais elaboradas como tese de doutorado nos anos 30. Na verdade, ao escolher ao Espanha, nosso geógrafo segue uma estratégia que começa a ser gestada no início do século XX. A internacionalização da geografia francesa é uma das prioridades dos seus mestres desde, pelo menos, a tese de doutorado de Emmanuel De Martonne, defendida em 1902. Para Dresch, De Martonne exercia uma política de internacionalização diferente de seus antecessores:

Contrairement à certains de ses collègues qui ont cru pouvoir écrire, parfois

brillamment, des volumes de la Géographie universelle sur des pays où ils n'avaient pas mis les pieds, il était persuadé qu'une expérience directe et étendue de pays 
variés était préférable et il a fait de son mieux pour permettre au plus grand nombre de faire du terrain (Dresch, 1973: 547). a ser orientadas por Emmanuel De Martonne, Lucien Gallois e posterioemente Albert Demangeon na Sorbonne, enquanto Jules Sion (Montpellier), Blanchard (Grenoble) e Camena d'Almeida (Bourdeaux) orientavam teses nas respectivas províncias (Clout, 2013). No fim da década de 20, alguns orientandos de De Martonne, Demangeon e Bernard completam seus trabalhos.

René Lespès fora aluno de Bernard e defendera uma tese de geografia urbana das regiões norte africanas. Tendo adquirido um posto de professor em um liceu em Algiers, é assim que ele leva a cabo sua pesquisa. A mesma estratégia foi adotada por François Bonniard que conseguira defender um trabalho em Bizerta, enquanto desenvolvia uma monografia regional sobre o Tell da Tunísia. O terceiro discípulo de Bernand era Jean Despois, que deixara o norte da França para desenvolver um trabalho sobre Tunis (Clout, 2013). As teses sobre a Espanha defendidas na década de 20 são representadas por Arthuer Gedes e Maurice Legendre. Este, por sua vez, encontrará Pierre Monbeig na Casa de Velásquez:

Also in 1927, Maurice Legendre completed a monograph on the impoverished Jurdes region of western Spain, with the patronage of Camena d'Almeida. Since 1910, its author had spent many summers in the area and had acquired a great deal of information, however his thesis proved to be a strange mixture of folklore, sociology, psychology, poetry and field observations. Completion of the doctorate did not change his career and he remained director of the Casa Velasquez (French Institute) in Madrid, nonetheless his text would inspire Luis Buñuel to make an early film, 'Las Hurdas: Tierra sin Pan'." (Clout, 2013).

Tornado professor em condições de orientar teses na Sorbonne em 1921, Albert Demangeon também não prescinde de contribuir na estratégia de internacionalização da geografia francesa. Ele deu suporte a alunos que desenvolveram teses sobre o estrangeiro no domínio da geografia urbana, política, rural, entre outros temas, em muitos países que ele mesmo visitou. Georges Lamaître, por exemplo, desenvolveu uma monografia regional sobre o English Weald; Louis Goblet dedicou-se a conquista inglesa do século XVII na Irlanda, enquanto Maurice Baumont desenvolveu uma distinta tese sobre a indústria de extração de carvão da Alemanha (Clout, 2013).

Mas qual era a proporção de teses sobre espaços alhures perto das monografias regionais francesas? No período de 1920 à década de 40, as monografias não metropolitanas praticamente se igualam às monografias metropolitanas (24 contra 35 ) e, se observamos os anos subsequentes, as monografias estrangeiras chegam a ultrapassar as monografias regionais francesas (63 contra 55) (Clout, 2013). Desde a institucionalização da geografia, o projeto editorial da Géographie Universelle, liderado por Vidal de la Blache e Lucien Gallois, e o esforço continuado de seus discípulos, como De Martonne e Demangeon, este, por sua vez, orientador da tese de Pierre Monbeig sobre as ilhas Baleares, aclara a vocação internacionalista da geografia francesa. 0 projeto sobre a Espanha de Pierre Monbeig não está, portanto, deslocando do projeto de uma escola, mesmo que, como veremos, esta escola seja permeada, nesse momento, por algumas fissuras.

Terra Brasilis, 5 | 2015 


\begin{tabular}{|l|l|l|l|l|l|l|}
\hline Período & $1893-1913$ & $1920-1942$ & $1945-1969$ & $1905-1917$ & $1922-1945$ & $1946-1966$ \\
\hline Número de monografias & 13 & 24 & 63 & 10 & 35 & 55 \\
\hline
\end{tabular}

\section{Duas Baleares: as ilhas espanholas como terreno de controvérsia, o espaço deixado por Jean Brunhes e atualização da perspectiva geográfica}

Isto posto, fica claro que, nessa conjuntura, diversas condições simultâneas aproximam Pierre Monbeig ao mundo estrangeiro, ao mundo latino, aos países novos e à Espanha. No que toca à mobilização de uma herança formativa para elaborar um trabalho sobre uma ilha espanhola, as estratégias de posicionamento do campo geográfico francês também oferecem respostas igualmente interessantes.

A opção de desenvolver uma tese sobre as ilhas Baléares também implicava movimentar as peças em jogo no interior do campo geográfico francês. ${ }^{9}$ Quais eram os personagens e fontes que representavam o conhecimento francês e espanhol na década de 30? Robert Ferras fala em um vazio de discursos e fontes, mesmo que Pierre Monbeig conte por variadas vezes com o apoio do Office comercial français, alguns guias de viagem, as revistas da Câmara de Comércio de Madrid e as publicações técnica de confederações hidrográficas (Ferras, 1991: 69).

Para completar a lista, Pascual Madoz aparece como uma referência recorrente, bem como o Diccionario geográfico, estadístico, histórico, de España y sus posesiones de Ultramar, publicado entre 1845 e 1850. Havia também a enciclopédia España e a Geografia Universal de Elisée Reclus. De um ponto de vista mais recente, Hermann Lautensach publicara em 1932 sua 'Zur Geographie der Künstlichen Bewässerung auf des iberischen Halbinsel', M. N. Schveitzer abordara a vida econômica da Espanha, com algumas passagens geográficas, e o livro relativo à Península Ibérica da Geografia Universal de Vidal de la Blache e Lucien Gallois, que fora publicado em oito tomos em 1931, não contava ainda com a Península Ibérica (Ferras, 1992: 69).

Um importante geógrafo catalão, Pau Vila, publica, em 1928, uma obra chamada Resum de geografia de Catalunya, de caráter didático e popular; Pascual Carrion traz a público em 1932 Los latifúndios em España, su importância, orgien, consecuencias y solucion; Germaine Picar et Jules Moch são financiado pela Rieder no livro L'Espagne républicaine em 1933 (Ferras, 1991: 70). Mas, de um ponto de vista estritamente geográfico, o maior intelectual que lograra dar uma contribuição mais significativa, no âmbito da Geografia Francesa, era ainda Jean Brunhes (Ferras, 1992: 69).

Com efeito, no período formativo de Pierre Monbeig, esse importante intelectual da Geografia francesa acabara de falecer (1930), depois de ter desenvolvido trabalhos sobre a Espanha. Jean Brunhes consagrara sua tese à Península Ibérica (além da África do Norte) - defendida em 1902 - em que ele se dedica a estudar as huertas espanholas, como fará Pierre Monbeig no artigo sobre Alicante e Murcie. Além disso, ele publica, em 1911, um trabalho de Geografia Humana sobre as ilhas Baleares, tema este que marca sua carreira e reforça sua preferência à temática das ilhas (Robic, 1986). 
Mas a opinião de Pierre Monbeig sobre uma das maiores contribuições metodológicas de Jean Brunhes, ainda na ocasião da aula inaugural de Geografia Humana na Universidade de São Paulo (proferida em 1935), e que foi se consolidando na entre 1925 e 1930 (quando Pierre Monbeig frequenta o Instituto de Geografia da Sorbonne), é bastante crítica: "os dois grossos volumes de Jean Brunhes estão longe de satisfazer inteiramente os especialistas e foram escritos com a intenção de revelar aos meios cultos a existência de uma ciência nova (...)" (Monbeig, 1940: 9). De outra parte, o mestre de Pierre Monbeig na Sorbonne, Albert Demangoen, também possui uma concepção insular que se difere bastante da concepção de Jean Brunhes. Albert Demangeon era da mesma maneira um especialista em uma ilha: a Grã-Bretanha. Esta fora tema da sua contribuição à Geografia Universal. A Gra-Bretanha passara de estágios sucessivos de isolamento e circulação. A concepção insular de Demangeon é uma leitura dos espaços regionais como uma unidade aberta:

C'est dans l'isolement que commence l'histoire de la Grande-Bretagne; la mer se montre d'abord hostile. 'En sa qualité d'ìle, dit Vidal de la Blache, la GrandeBretagne a reçu plus tard que les nations continentales le contre-coup des événements qui se passaient en Europe; plus tard et autrement que la Gaule, l'influence romaine et les christianismes; plus tard et plus graduellement que les contrés rhénanes, les invasions germaniques. Elle est devenue une puissance commerciale plus tard que les Hanséates et un foyer industriel plus tard que les Flandres'. Les Anglais vécurent longtemps comme des laboureurs et des pâtres avant de devenir des marins. Et, même après avoir rompu l'encerclement des flots, ils conservent obstinément les démarches instinctives de la mentalité insulaire : l'attachement aux vieilles institutions, l'hésitation à imiter autrui, le goût de l'isolement parmi les étrangers, la volonté de garder leur race pure de tout mélange, l'idée fixe de ne jamais se créer des liens avec le continent, la défiance de toute relation qu'on ne pourrait pas rompre au moment utile. (...). L'archipel demeura excentrique tant que la Méditerranée fut le foyer du commerce du monde ; il changea réellement de position lorsque le commerce s'entendit aux mers du Nord de l'Europe, depuis la Baltique jusqu'à la Manche en passant par les détroits danois. Aux premiers siècles du moyen âge, on vit les marins et les marchands des pays du Nord quitter leurs föhrden et leurs fjords, s'aventurer au large et atteindre les rivages du grand archipel que fermait leur horizon occidental ; la renommée antique leur avait enseigné qu'il était riche en métaux précieux et en troupeaux. C'est ainsi que l'archipel britannique entra, passif encore, dans l'orbite économique des peuples maritimes du continent; il put seulement alors pressentir sa vocation océanique. 'La Grande-Bretange, dit Vidal de la Blache, dut, à ces acquisitions successives d'hôtes formés et endurcis à la mer, un trésor grossissant d'expérience nautique qui paraît avoir manqué à ses habitants primitifs. (Demangeon, 1927: 2-3).

A contribuição teórica de Demangeon se diferencia consideravelmente da herança legada por Jean Brunhes, para Robic " [Jean Brunhes] en usant des vertus d'un isolement supposé, obstacle à la diffusion, donc garantie d'authenticité, il s'accorde la possibilité d'observation du lien local entre cadre géographique et organisation sociales : à l'abri de l'emprunt, de l'imitation" (Robic, 1988: 38). Notável é também o fato de que a crítica ao trabalho de Jean Brunhes já tivera ressonância sob a pena de Vidal no que toca a ilusão de isolamento adotado por Jean Brunhes no contínuo processo de mundialização da economia:

C'est surtout, il faut bien le dire, par sa diversité des cas qu'est caracterisé le champ de comparaison embrassé par l'auteur. Il est plus douteux qu'on y trouve ce qu'il appelle 'une réelle unité ou mieux une réelle continuité geógraphie (Vidal de la Blache, citado por Robic, 1988: 40). 
Baleares em contraposição ao que fora escrito por Jean Brunhes. O cotejo dos trabalhos de Jean Brunhes e Pierre Monbeig sobre as ilhas Baleares ajuda a esclarecer essa tomada de posição do jovem geógrafo. O que se destaca, como ponto de partida, é o fechamento da ilha para Jean Brunhes, que se expressa no caráter da distribuição da sua produção interna: esta se volta mais a alimentação da população do que a exportação (Brunhes, 1911: 179). Ele não ignora que a vida insular é cada vez mais aberta ao estrangeiro, mas quase todo sua exposição se dedica a uma vida em condições distintivas, o andar de baixo da produção (Brunhes, 1911: 179). De outro ponto de vista, a relação com o estrangeiro é vista em relações unidirecionais. Ele fala de uma exportação da produção, mas não discorre sobre o que a vida de relações trouxe à dinâmica interna da Ilha. Assim, ele se aproveita do estudo das Baleares para ressaltar quase que exclusivamente uma dinâmica interna e arcaica da vida do Mediterrâneo:

Des les îles moyennes ou petites comme les baléares et en dehors des grandes cités comme la capital de Majorque, on reconnaît les traits distinctifs de la plus antique vie méditerranéenne. Peuples par excellence citadins, ou plus exactement 'urbains' presque tous les méditerranéens se sont groupés en des agglomérations aux maisons accolées, - si bien accolées et groupées que l'ensemble a l'aspect de petites villes, alors que ce sont de simples villages (Brunhes, 1911: 181).

Principiando o artigo de 1930, « Les transformations économqiques dans les 'huertas' et la réegion entre Alicantge et Murcie', uma nota inicial faz referência à obra de Jean Brunhes, ressaltando, em uma redação adversativa que, contudo: "L'activité particulière des huertas d'Alicante, Elche, Orihuela, Murcie est un fait bien connu; aussi voulons- 
nous seulement y indiquer les tendantes nouvelles de l'agriculture et de l'industrie." [grifos nossos] (Monbeig, 1930: 597). Além disso, o primeiro tópico, versando sobre a irrigação, mais de uma vez incide sobre os mesmos temas daquele geógrafo. 0 objeto de análise é o mesmo do de Jean Brunhes, só que com disposições teóricas discordantes.

Pierre Monbeig dá início aos seus trabalhos de campo nas ilhas Baleares no ano exato da morte de Jean Brunhes, em 1930: "la documentation de cette étude a été réunie pendant trois séjours aux Baléares effectués dans les années 1930 et 1931” (Monbeig, 1932: 538). Nos esboços de tese de Monbeig, a história dos espaços baleares percorre sucessivas mudanças de isolamento e de comunicação. Isto posto, as descobertas se anunciam a partir da indagação quanto à gênese da inserção das ilhas às tendências do mundo contemporâneo. Diversamente de Jean Brunhes, a ilha em nada é contemplada como um laboratório de traços distintivos e de relações isoladas. Um espaço de fluxos, correlações a um conjunto econômico mais vasto, precipitam a consciência da ilusão da unidade natural. Visto por esse ângulo, o título do artigo, divulgado como resultado parcial de seus trabalhos de tese, faculta pouca margem a enganos: "Vie de relations et spécialisatioin agricole, les Baléares au XVIIIe siècle" [grifos nossos] nos parece uma singela definição de posições:

Nous possédons, sur les Baléares, plusieurs études récentes, d'un vif intérêt. Mais elles portent exclusivement sur le moyen âge qui fut lá l'époque entre toutes glorieuse. Les frondeur d'Hannibal puis, après la conquête chrétienne par Jaime Ier, l'étonnante activité commerciale de Majorque depuis 1229 jusqu'au moment où la Méditerranée fut abandonnée pour l'Atlantique, voilà les seules images qu'évoque, á l'ordinaire, le passé de l'archipel. A partir du XVe siècle environ, le port de Palma cessa d'être visité par les trafiquants italiens et l'on abandonne les relations avec les oasis sahariennes; les Majorcains des champs se révoltèrent contre la domination financière des citadins; le rattachement de plus en plus étroit du territoire à la puissance castillane fut accompagné par une sévère législation commerciale et les îles se replièrent sur elles-mêmes. Aujourd'hui le tableau a changé : ni l'industrie ni le commerce de la reconquête n'ont revécu, mais l'arboriculture est devenue la grande richesse. Il y a donc eu une complète transformation de l'économie. Ce fut de l'étranger que directement ou non, après deux longs siècles confus de luttes locales, Minorque et Majorque reçurent, au cours du XVIIIe siécle, un élan nouveau [grifos nossos] (Monbeig, 1932: 538).

O destaque da interconexão da ilha com espaços mais vastos é tão importante para Pierre Monbeig que ele anuncia que uma história geográfica tem como base os fluxos e as relações horizontais e que os processos econômicos das Ilhas Baleares têm origem fundamentalmente na relação com o estrangeiro, como já assinala a citação precedente. Situar a origem dos processos geográficos locais no estrangeiro (desde o século XVIII!) é um raciocínio tão distinto em relação às observações de Jean Brunhes que temos a impressão muitas vezes de se tratar de duas ilhas diferentes. Ora, discordando de Jean Brunhes e promovendo uma atualização do legado de Vidal cujo professor Albert Demangeon vinha se dedicando, Pierre Monbeig começa a construir uma carreira universitária trilhando um caminho particular.

\section{As ilhas Baleares como primeiro modelo da colonização moderna nas franjas pioneiras}


de disputa. Neste mesmo século, a condução política da ilha passa pelas mãos dos ingleses, franceses e espanhóis. Diferentes situações políticas orientam distintas normas de valorização. Contudo, a valorização e modernização desses espaços vem de fora: "Ainsi il avait fallu le gouverment de l'Anglais Kane pour amener les Minorcains à dominer les mauvaises conditions naturelles et éveiller l'agriculture" (Monbeig, 1932: 541). Foi a obra dos ingleses, notadamente do governo de Kane, atuando entre $1712 \mathrm{e}$ 1736, que começa a mudar todo o estado de coisas (Monbeig, 1932: 539).

Com a instalação da segurança contra os corsários na ilha, a derrubada da floresta avança, bem como o saneamento de águas estagnadas e a fundação de cidades, tudo isso age como a construção de uma "franja pioneira":

Grâce à la flotte anglaise, les Barbaresques cessèrent d'être redoutables et, la sécurité revenue, il fut possible de défricher le pourtour de Minorque. Des travaux de dessèchement des parties basses et marécageuses furent menés à bien au voisinage de Mahon et Kane funda un village à Villa Nueva de San Carlos, exemple que suivirent, quelques années plus tard, les Français à San Luis, non loin de Mahon (Monbeig, 1932: 539).

A situação geográfica inicial parte da necessidade de conquistar o terreno em conflito com condições naturais de difícil dominação. 0 processo de valorização de novas terras implica a construção de estradas, dado que estas ligam os mercados. Todo o percurso da produção local do espaço é estimulado pela economia internacional. A valorização de vastas áreas é também associada, neste primeiro momento, à vinculação ao mercado de exportação. A situação marítima e comercial permite a acumulação de capital para o reinvestimento na indústria (Monbeig, 1932: 541). Todo este estado de coisas depende, para Monbeig, da vontade política. 0 regime de propriedade se transformou e a grande propriedade sofre aumento significativo (Monbeig, 1932: 540). É assaz surpreendente como essa conquista de novas terras é bastante próxima da posterior descrição das franjas pioneiras. A elucidação da lógica interna das dinâmicas de áreas de colonização se apresenta para um Monbeig quase como um modelo.

A compreensão da mudança do nível de vida material de amplos setores de população está no centro de seu trabalho. Nas ilhas Baleares, essa transformação é situada por Monbeig no século XVIII. Sendo assim, o fenômeno para o qual está atento é o da valorização de novas terras em Maiorca e Minorca, revelando, sob outra perspectiva, um primeiro contato com o processo econômico que ele observará no Brasil: a valorização das terras de colonização. Ora, a conclusão mais evidente do estudo de Monbeig é que o processo de valorização dos cultivos nos espaços modernos que se desenrolam a partir do século XVIII se dá através de impulsos externos:

Pendant près de cent ans, Minorque fut occupée par les troupes françaises et surtout anglaises qui marquèrent profondément la civilisation locale. D'une part, l'homme s'efforça de tirer parti des faibles ressources naturelles et, d'autre part, l'industrie et le commerce, grâce à une situation politique favorable, purent s'exercer en toute sécurité et liberté. La terre de Minorque fut proprement mise en culture au XVIIIe siècle. Jusqu'alors, en effet, les paysans, menacés par les incursions des pirates barbaresques, ne cultivaient que le terres de Centre, dites 'Mitijania', laissant incultes et couvertes de pierre celles du Nord et du Sud (Monbeig, 1932: 538-539).

Pour compléter ce labeur de reconstruction, l'établissement d'une route fut commencée en 1713 et achevée en 1720 pour relier les deux marchés de Ciudadela et de Mahon. Enfin l'action de Kane se porta sur le commerce des produits agricoles. Ses règlements commerciaux contenaient, en même temps que de sages 
prescriptions, des conseils impératifs adressés aux paysans. Chacune de ses ordenances comporte une partie purement agricole et une partie traitan du trafic. L'ordennance sur le bétail débute par quelques recommendations énergiques sur les haures de pâture en été et s'achèce par la fixation des prix de vente. On se vit le résultat dans le développement de l'exportation de fromage vers l'Italie dont le produit annuel atteignit 800 [libres]" (Monbeig, 1932: 540).

Contudo, a sucessão de forte política colonial, do governo inglês ao governo espanhol, resulta em uma baixa comercial da ilha: "Le Gouvernement de Madrid paralysa l'économie de l'île" (Monbeig, 1932: 542). Mas uma mudança da mentalidade econômica e uma nova abertura ao comércio transatlântico reascende um novo momento de trocas. Sem detalharmos os tipos de políticas econômicas que representaram os diferentes governos, atentamos à conclusão de Pierre Monbeig e o quanto ela difere da proposição de Jean Brunhes:

Ainsi l'archipel avait repris sa place dans le trafic général. Certes ce n'était plus dans le cadre méditerranéen du moyen âge. Mais l'exemple est instructif. Le groupement insulaire, plus encore que la région continentale, s'accommode mal de l'isolement et d'un strtict protectionnisme. Tant que le Gouvernement castillan fut seul à diriger Majorque, tant qu'il fallut vivre des l'étroite sphère de la péninsule ibérique, les îles végétèrent. Le XVIIIe siècle, en élargissant leur horizon, les orienta vers une nouvelle prospérité (Monbeig, 1932: 548).

Quadro 1: exemplo do modelo das franjas pioneiras já notáveis no estudo de Pierre Monbeig sobre a Espanha (1932)

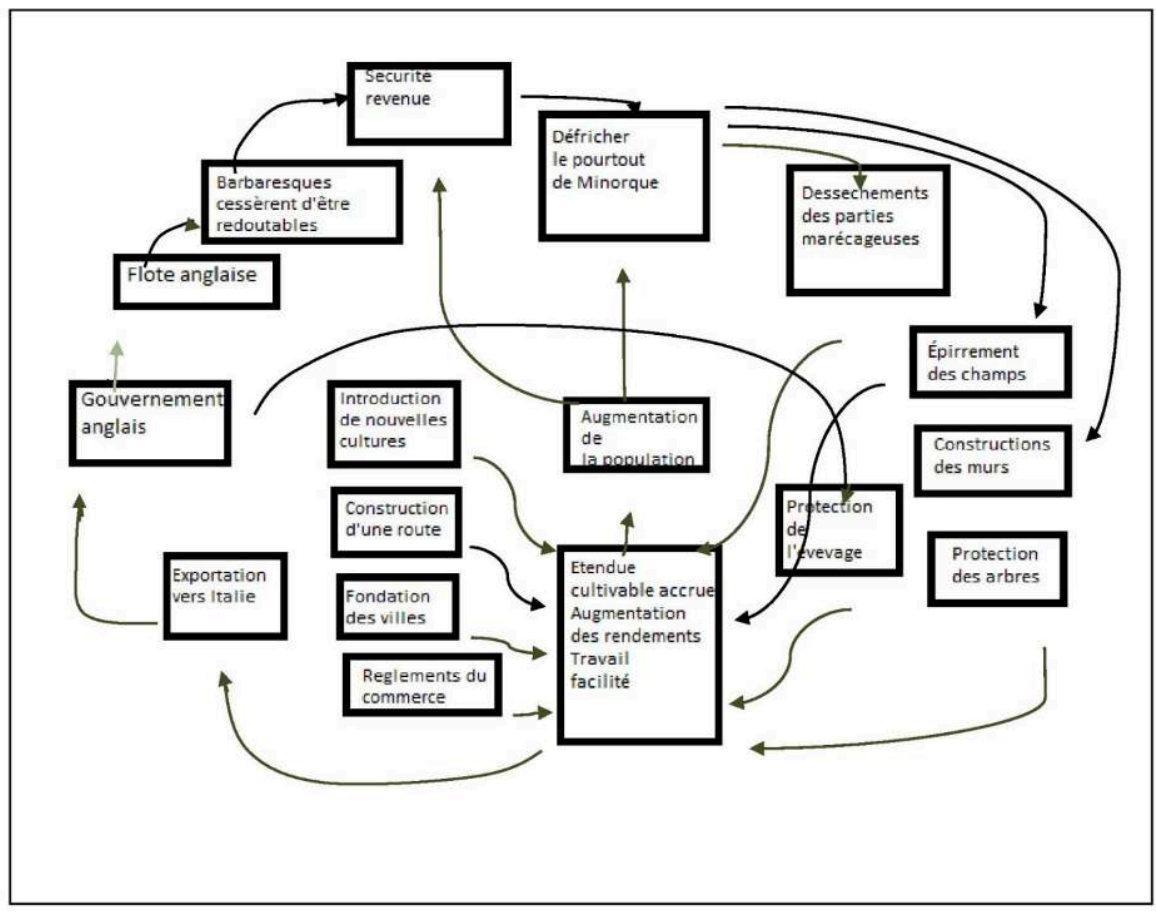

51 Ademais, ao escolher como objeto de tese os espaços de colonização, Pierre Monbeig retira daí o primeiro esboço do modelo que se aperfeiçoará no estudo das franjas pioneiras no Brasil. Com diferentes graus de aprofundamento, os elementos em causa ajudam a explicar a colonização das terras incultas da Ilha e são supreendentemente semelhantes aos das zonas de colonização paulistas. 
quadro 1 apresenta os mesmos fenômenos que serão mais profundamente analisados na ocasião dos trabalhos sobre as franjas pioneiras no Brasil: estímulo do Estado, desmatamento, extensão da área cultivada, construção de estradas, fundação de cidades, aumento da população, exportação ao mercado externo, estabelecimento propriedade, especialização agrícola etc. Além disso, a base do raciocínio de Pierre Monbeig é sistêmico e a consideração desses fatores econômicos são externos ao conjunto regional no contexto do após guerra. Parte desses elementos das franjas pioneiras estão sintetizadas na citação abaixo:

Tudo se passa como se este país conhecesse em setenta e cinco anos, um século no máximo, o que se levou milênios para fazer na Europa. E certamente é isso: nascimento e formação da paisagem rural, fundação e crescimento das cidades, construção duma rede de comunicações, mistura de raças, elaboração de uma mentalidade regional, tal o imenso trabalho que ainda prosseguia, aos nossos olhos (Monbeig, 1984: 23).

Do ponto de vista teórico, um dos elementos essenciais do método geográfico que aparecem nos escritos de Monbeig sobre as Baleares é o tratamento sincrônico e diacrônico das explicações da Geografia francesa. ${ }^{10}$ Marie-Vic Ozouf Marignier vincula a ideia de que as relações horizontais no tratamento geográfico aos "mauvais pays" se consolida nos anos 1920, estando Pierre Monbeig, destarte, em perfeita consonância com o seu contexto científico. Os "mauvais pays" são lugares inférteis de difícil adaptação humana:

A la fin des années 1920, les géographes font intervenir un nouveau paramètre dans la lecture de la relation homme-milieu dans ces mauvais pays. Alors que jusque-là ils avaient eu tendance à privilégier les causes endogènes de la mise en valeur des pays selon une vision 'internaliste', ils envisagent de plus en plus volontiers une causalité exogène relativement à l'accomplissement du progrès ou à frein (OzoufMariginer, 2000: 83). ${ }^{11}$

Impressionando-se com tal dinamismo, nosso personagem elegerá a Espanha, e não o Brasil, como primeiro palco de reflexão sobre os espaços de colonização, tema este que não está ausente, aliás, das clássicas considerações de Vidal de la Blache e Albert Demangeon. Por certo, Vidal de la Blache já estabelecera um programa de pesquisa que consistia em compreender a expansão dos gêneros de vida aos novos territórios. A origem do gênero de vida, tema do primeiro artigo publicado por Vidal, se dá em quadros compartimentados da natureza (Vidal de la Blache, 2012 [1911]: 156-157). Uma segunda etapa, contudo, consiste no irradiamento dos gêneros de vida "mais evoluídos" para grandes extensões continentais.

Tais gêneros de vida, porém, tendem a se confinar e a se restringir. A agricultura e a pecuária, ao contrário, não pararam de estender seus domínios, de dar lugar a variedades e a subgêneros cujas diversas ramificações penetram até as partes mais inóspitas dos continentes. Desde os estágios primitivos - onde a diferença se traduzia apenas por uma divisão de atribuições entre o homem caçador e a mulher dedicada a alguns cultivos ao redor das cabanas -, o progresso desses dois gêneros de vida [agricultura e pastoreio] foi tão grande que eles praticamente conseguiram concentrar, pela divisão do trabalho, todas as forças da coletividade, empregando-as em qualquer época do ano. Desse modo, eles realizam plenamente o que Ratzel denomina muito bem "formas de vida nas quais toda atividade e todo esforço "recebem" uma direção particular" (Vidal de la Blache, 2012 [1911], 2º artigo: 160). 
Do cotejo das obras de Pierre Monbeig e Jean Brunhes pode-se perceber que a escolha da temática de uma ilha espanhola visava a oferecer uma nova interpretação à compreensão dos espaços insulares no contexto da nova interdependência das regiões do mundo, definidas aqui como sendo o processo de mundialização. Pierre Monbeig incide sobre os mesmos temas que Jean Brunhes e, em algumas passagens, os termos escolhidos visam a reforçar uma contraposição frente a este outro intelectual: "vida de relações", por exemplo, posto no título sobre as ilhas Baleares, é um exemplo notável. Para esta contraposição, ele ladeia suas estratégias às concepções insulares de Vidal de la Blache e Albert Demangeon.

\section{Considerações finais}

57 Por que Pierre Monbeig escolhera a Espanha? Há, por certo, o peso da proposição de Albert Demangeon, mas também um encanto pelas terras do Midi, um idealismo cultural e político envolvido nessas opções, incitado pela conjuntura política desse país. É nesse momento que Pierre Monbeig se posiciona pelo fortalecimento do Estado e por um socialismo reformista, que está em plena consecução nos projetos espanhóis. Mas há também um pragmatismo econômico, uma vez que a França começa a reavaliar suas relações com o estrangeiro ao enfrentar uma conjuntura de crise. A França elege o mundo latino como sua área de influência, ávida em assegurar sua atuação na Espanha e na América Latina. Pierre Monbeig não prescinde desta mobilização nacional.

Assim, outros eventos induzem a escolha de Monbeig: um contexto de conflito econômico, mas também científico. Os geógrafos franceses também estão engajados na diplomacia cultural. A antiga política cultural exercida no Mediterrâneo pelas escolas de Atenas e de Roma é incrementada em 1928 pela Escola de Madrid. A década de 30 é um ponto de inflexão da intensificação da propaganda cultural francesa; Emmanuel De Martonne cria uma série de oportunidades de atuação dos geógrafos em diversas instituições e que lhe possibilitam estudos do estrangeiro: na diplomacia, na associação dos geógrafos franceses e na Escola de Estudos Hispânicos; a Espanha é o mais novo foco dessa diplomacia.

Há uma internacionalização da geografia francesa? Apesar das dificuldades, a geografia francesa foi marcada, desde pelo menos a tese de De Martonne, por estudos nãometropolitanos e a tendência se intensifica com as monografias regionais orientadas por ele e por Demangeon, de forma que seguem uma curva de crescimento no período em que Pierre Monbeig desenvolve sua tese. Não se sustenta, portanto, a caracterização de uma geografia francesa afastada de embates políticos, de disputa de projetos nacionais e científicos, fechada sob os quadros das regiões francesas. As escolhas de Monbeig também dizem muito sobre o contexto científico da geografia francesa nesse momento: primeiro, fica evidente que havia possibilidade de escolha, bem como espaço para uma postura crítica e relativamente aplicada dos estudos geográficos. Além disso, intentamos demonstrar que a geografia francesa está plenamente engajada, nesse período, nos estudos dos processos econômicos globais e em uma atualização do paradigma vidaliano e sua aplicação aos processos de mundialização.

Neste momento, Pierre Monbeig toma o primeiro contato com as dinâmicas internas e externas dos espaços de colonização, chamados também de pays neufs num contexto de mundialização. Da rusticidade dos espaços mediterrâneos, a dificuldade de conquista do 
meio resguarda a existência de terras de colonização ainda no século XX, cujos grupos políticos estão no centro desse movimento.

61 E no interior do campo geográfico francês? Existe uma disputa de narrativas no que toca aos estudos insulares espanhóis. Acreditamos que a morte de Jean Brunhes, em 1930, abre a possibilidade de construção de um novo especialista hispânico. Pierre Monbeig procura também um posicionamento no mundo científico e no campo geográfico. A Espanha possuía características de um país novo também pelas dificultosas condições de trabalho e por um vazio de estudos geográficos cujo mais significativo para o meio acadêmico francês ainda datava ainda do começo do século, empreendido por Brunhes.

Assim, mais do que uma inspiração temática, é na Espanha que ele elabora o esboço de um primeiro modelo das dinâmicas do que ele irá chamar de franjas pioneiras, em trabalhos que versam sobre o passado e o sobre o presente com um instrumental teórico comum, onde estão em jogo a influência do mercado externo, a expansão da grande propriedade, a importância da técnica, a produção agrícola especializada, os novos meios de transporte, a fundação de rede de cidades, a melhoria de qualidade dos produtos, o aumento do consumo e a vinculação a um mercado universal.

63 A especialização da Geografia Humana fica clara quando ele adota raciocínios causais sistêmicos, ou um raciocínio cíclico no interior de uma estrutura liderada pelo fator externo e humano. $O$ método geográfico é seletivamente valorizado em função de um contexto histórico e espacial. Com efeito, a Primeira Guerra Mundial e a crise econômica passaram a valorizar o aspecto do princípio da extensão e da unidade do método geográfico, atualizando a perspectiva geográfica rumo à compreensão da nova realidade de mundialização.

\section{BIBLIOGRAFIA}

ARRAULT, Jean-Baptiste (2007). Penser à l'échelle du Monde. Histoire conceptuelle de la mondialisation en géographie (fin du XIXe siècle/entre-deux-guerres). Thèse de doctorat soutenue dans l'Université Paris 1- Panthéon-Sorbonne pour l'obtention du titre de docteur en Géographie.

BASFAO, Kaoem. HENRY, Jean-Robert (1991). Le Maghreb et l'Europe: que faire de la Méditerranée?. Vingtième Siècle. Revues d'histoire. Vol. 32, numero 1.

BATAILLON, Claude (1991). Entretien avec Claude Bataillon. Les années de formation. In: THÉRY, H. DROULERS, M. Pierre Monbeig un géographe pionnier. Paris : IHEAL.

BERDOULAY, V. (2008). La formation de l'école française de géographie: 1870-1914. Paris: CTHS.

BOURGUET, Marie-Noëlle (1998). De La Méditerranée. In: BOURGUET, Marie-Noëlle; LEPETIT, Bernard; NORDMAN, Daniel; SINARELLIS, Maroula [dir]. L'Invention Scientifique de la Méditerranée. Égypte, Morée, Algérie. Paris: Ed. De L'École des hautes études en sciences sociales. 
BRUNHES, J. (1911). A Majorque et a Minorque. Esquisse de Géographie Humaine. Revue des deux mondes. T. 6, 1911, pp. 175-196.

CLAVAL, P. (1984) Géographie Humaine et économique contemporaine. Paris : PUF.

CLAVAL, P (1988). Le Géographes français e le monde méditerranéen. Annales de Géographie, XCVII, n. 542, p. 385- 403.

CLOUT, H. (2013) « Professorial patronage and the formation of French geographical knowledge. A bio-bibliographical exploration of one hundred non-metropolitan regional monographs, 1893-1969 », Cybergeo : European Journal of Geography [En ligne], Epistémologie, Histoire de la Géographie, Didactique, document 549, mis en ligne le 17 octobre 2011, consulté le 01 octobre 2015. URL : http://cybergeo.revues.org/24203 ; DOI : 10.4000/cybergeo.24203

DE MARTONNE, E (1934). Institut de Géographie. Annales de l'Université de Paris, 9e année, n.3.

DELAMARRE, J. -B (1975). M. Jean Brunhes (1869-1930). Bulletin de la Section de Géographie. t. LXXXI. Paris: Bibliothéque Nationale.

DELAUNAY, Jean-Marc (1994). Des Palais en Espagne. L'École des hautes études hispaniques et la Casa de Velázquez au cœur des relations franco-espagnoles du XXe siècle (1898-1979). Madrid : Casa Velázquez.

DELFOSSE, C. (2001) Emmanuel de Martonne, tisseur de réseaux internationaux de géographes. In: BAUDELLE, Guy; OZOUF-MARIGNIER, Marie-Vic; ROBIC, Marie-Claire. Géographes en pratiques (1870-1945), le terrain, le livre, la cité. Rennes: Presses Universitaires. cap. 12, pp. 189-206.

DEMANGEON, A (1934). Économie agricole et peuplement rural. Annales de Géographie, t. 43, n. 241, pp. 1-21.

DEMANGEON, A. (1937). La Méditerranée. Annales de Géographie, vol. 46, n. 261, pp. 307-308.

DEMANGEON, A (1927). Les îles britanniques. In: VIDAL DE LA BLACHE, P. GALLOIS, L. Géographie Universelle, tomo 1. Paris: Armando Colin.

DEPREST, Florence (2002). L'invention géographique de la Méditerranée: éléments de réflexion. Espace géographique. 1, n³1, pp. 73-92.

DRESCH, J (1973). Emmanuel De Martonne, organisateur de la géographie française. Bulletin de l'Association des Géographes français. 408-409, pp. 543-549.

FERRAS, R. (1991). L'Espagne des années trente. In: THÉRY, H. DROULERS, M. Pierre Monbeig un géographe pionnier. Paris : IHEAL.

FERRO, M. (1996). História das Colonizações. Das conquistas às Independências. São Paulo : Companhia das Letras.

FOHLEN, C (1985). Francia 1920-1970. In: CIPOLLA, C. M. Historia economica de Europa (6). Economias contemporaneas. Barcelona: Ariel.

GALLOIS, L. (1931). Le congrès international de géographie de Paris. Annales de Géographie, vol. 40, n. 228, pp. 577-590.

GRAN-AYMERICH, J.; GRAN-AYMERICH, E. (1992). La création des Écoles françaises d'Athènes, Rome et Madrid. Communications, 54, pp. 175-187.

LIRA, L. A. (2013). O Mediterrâneo de Vidal de la Blache: o primeiro esboço do método geográfico (1872-1918). 1. ed. São Paulo: Alameda; Fapesp.

MONBEIG, P. (1991). La réforme agraire en Espagne. In: THÈRY, H. DROULERS, M. Pierre Monbeig un géographe pionnier. Paris: IHEAL. 
MONBEIG, P. (1930). Les transformations économiques dans les huertas et la région entre Alicante et Murcie. Annales de Géographie, 1930, t. 39, n. 222, pp. 597-606.

MONBEIG, P (1932). Vie de relations et spécialisation agricole : les Baléares au XVIIIe siècle. Annales d'histoire économique et sociale, 4 e année, n. 18, pp. 538-548.

MONBEIG, P. (1940). Que é geografia? Aula Inaugural do Curso de Geografia Humana. In: MONBEIG, Pierre. Ensaios de Geografia Humana Brasileira. São Paulo: Martins: cap. 1, pp. 9-17.

OZOUF-MARIGNIER, M.-V. (2000). Les géographes français et les 'mauvais pays', 1890-1930. In: BERDOULAY, Vincent ; SOUBEYRAN, Olivier. Milieu, colonisation et développement durable. Paris : L'Harmattan cap 5, pp. 73-84.

ROBIC, M. -C. (2006). L'école française de géographie: formatage et codification des savoirs". In: PELUS-KAPLAN, M. -L.(dir.). Unité et globalité de l'homme. Des humanités aux sciences humaines. Paris: Syllepse.

ROBIC, M. C. (1986). Ile, vallee, oasis : la monographie exemplaire ? COnference regionale sur les pays méditerranéens. Groupe de travail sur l'histoire de la pensée géographique, Barcelone.

ROBIC, M. C. (1988). Les petits mondes de l'eau : le fluide et le fixe dans la méthode de Jean Brunhes. L'espace géographique, n. 1, pp. 31-42.

ROBIC, M-C. (1996). Des vertus de la chaire à la tentation de le l'action. In: CLAVAL; P. SANGUIN A. L. (dir). La Géographie française à l'époque classique (1918-1968). Paris: L'Harmattan.

SION, J. (1934). La France Méditerranéenne. Paris: Armand Colin.

SUPPO, H (2000). A Política Cultural da França no Brasil entre 1920 e 1940: o direito e o avesso das missões universitárias. Revista de História 142-143, pp. 309-345.

UNIVERSITÉ DE PARIS, (1935), Annales de l'Université de Paris, 10e année, n. 3.

UNIVERSITÉ DE PARIS. (1929) Inauguration de l'Institut d'études hispaniques de l'Université de Paris. Annales de l'Université de Paris, 4e année, n. 3.

VIDAL DE LA BLACHE, Paul. [1911] (2002) Os gêneros de vida na Geografia Humana. Geographia, vol 7, n. 13.

VIDAL DE LA BLACHE, P (1994). Tableau de la Géographie de la France. Paris: Le Table Ronde.

\section{NOTAS}

1. Nascido em 1869 e morto em 24 de agosto de 1930, Jean Brunhes frequentou o liceu Lous-leGrand. Em seguida, Jean Brunhes se decide pela Geografia em 1891, quando resolve fazer uma tese em Geografia sob a influência direta de Vidal de la Blache. Em 1892, ele é aprovado no concurso da Agrégation em História e Geografia. Hesitante em ingressar na Escola de Atenas, como fez Vidal, ele acaba por se decidir a realizar seus estudos na Foundation Thiers, récem fundada e lá fica entre os anos de 1893 e 1896. Depois, ingressará como professor na Université de Lille. Nesta universidade, toma uma decisão corajosa, ao intitular seu curso de 'Geografia Humana', sendo a primeira vez que aparece o termo no meio acadêmico (Delamare, 1975: 50-51).

2. Geógrafo francês nascido em 1908, formado no Instituto de Geografia da Sorbonne, Pierre Monbeig integrará, aos 27 anos, a missão francesa que será enviada à Universidade de São Paulo, fundada em 1934, para ajudar a organizar o curso superior de História e Geografia. Chegando ao Brasil em 1935, ele terá um papel chave na fundação da Geografia brasileira sob os aportes da Geografia francesa. 
3. Desde o fim do século XIX e início do XX, as comunidades científicas experimentaram um internacionalismo crescente, com a multiplicação de congressos internacionais e a colaboração entre as associações. Isso é instado a um novo contexto no fim da primeira guerra. A economia é mundializada. As relações bilaterais no âmbito político e cultural passam a outro patamar. 0 período é marcado por fissuras no âmbito dos discursos da ciência e da cultura que reproduziam interesses nacionais. Alçado a um novo patamar de unidade e concorrência, o Conselho internacional de pesquisas (CIR), começa a se destacar de outras associações e criar um novo universalismo científico. A criação do CIR desfavorece associações de 'sábios', distantes da aplicação das ciências às demandas de reconstrução. Além do que, a partir da organização que lhe dá origem, a Academia de Nações Aliadas, passa a reproduzir conflitos geopolíticos no âmbito do diálogo científico internacional (Robic, 1996: 30). Neste campo, a comunidade internacional de pesquisadores começa a pressionar crescententemente pela exclusão das potências centrais desses diálogos, "sous le prétexte que les savants de ces pays se sont mis eux-mêmes au ban de la communauté scientifique par leurs prises de position dans le conflit" (Robic, 1996: 30) e pela definição de áreas de influência.

4. Quando Vidal de la Blache se enreda no processo de institucionalização da geografia francesa, ele o faz a partir do enfretamento com objetos e correntes clássicas (Lira, 2013). Ainda que sua geografia tome a França como principal espaço de referência, há também à vinculação a uma ampla zona cultural. O Mediterrâneo não resume a importância que Tableau de la Géographie de la France representa para a continuidade da geografia regional francesa (ROBIC, 2003, p. 87), mas ele não deixa de se anteparar nesta tradição geográfica (Claval, 1988). As contribuições de Vidal de la Blache sobre o Mediterrâneo acompanham toda a sua carreira: Hérodes Áttique. Étude Critique sur sa Vie (1872), Péninsule Européenne. L'océan et La Méditerranée. Leçon d'ouverture du cours d'histoire et géographie a la Faculté des Lettres de Nancy (1873), L'Europe Méridionale et le monde méditerranée (1875), Des rapports entre les populations et le climat sur les bords européens de la Méditerranée (1886), États et Nations de L'Europe, Autour de la France (1889), Les Civilisations Africaines d'après Frobenius (1899), La Zone Frontière de L'Algérie et du Maroc d'Après de Nouveaux Documents (1897), La Conquête du Sahara (1911), Les Grandes Agglomérations Humaine (1918).

5. Foram os naturalistas e intelectuais franceses que deram origem a ideia de uma região mediterrânea (Bourget, 1998). A partir do século XVIII, o recolhimento de amostras caminha de par com a transformação do olhar científico. O que antes se caracteriza como missões que visavam recolher excentricidades são, a partir de então, orientadas para a observação das regularidades, no espírito de permitir comparações de uma ciência que ambiciona a construção de uma visão da universalidade (Bourget, 1998). Os viajantes franceses enviados para missões no Egito (1798-1801), na Moréia (1829-1831) e na Argélia (1839-1842) recolhem dados que serão colocados em quadros comparativos quando do retorno ao Museu de História Natural (Bourget, 1998: 18) e dão conteúdo a uma região mediterrânea.

6. Para fazer face à Prússia, a França objetiva se alçar como uma herdeira das civilizações grecoromanas, elaborando um discurso de unidade do mundo latino: “Or, dans les premières années du $\mathrm{xx}$ siècle, alors que dans les pays latins la vie intellectuelle prend un nouvel essor, en réaction contre le pangermanisme et l'admiration exclusive professée pour la science allemande après 1870, apparaît l'idée d'une 'Union latine' dans laquelle la France jouerait le rôle d'intermédiaire entre les nations (Luchaire 1924)" (Gran-Aymerrich e Gran-Aymerrich, 1991 : 183).

7. A construção da centralidade francesa moderna continua a se intensificar depois da derrota de 1870. Nesta nova conjuntura, subjacente ao discurso da ocidentalização da cultura está tanto a posição de força da França numa zona latina, quanto, por oposição, a relativa fraqueza dos aliados mediterrâneos como a Itália e a Espanha. Mas o essencial dessa estratégia é erigido sob a ameaça germânica: é na disputa geopolítica com a Alemanha que o discurso francês latino tomará força. Ele visará a construir a inserção da Alemanha num domínio cultural oriental uma vez que, 
para a França, a tomada da Alsácia e da Lorena pelos alemães os aproximava dos métodos orientais, notadamente dos russos, cuja diferenciação entre a expansão colonial e territorial não existia (Ferro, 1996: 20). Na passagem do século XIX para o início do XX, a França continuará a tentativa de se alçar como a herdeira de um patrimônio cultural e como legítima promotora de missões civilizacionais. Essa longa duração do discurso civilizatório também terá importantes reflexos na política colonial. Segundo Ferro, entre as enormes diferenças dos projetos coloniais europeus, era lugar comum a ideia de que a colonização francesa na África do Norte se diferenciava da colonização inglesa no tocante à crença que a impulsionava: enquanto a Inglaterra se preocupava com a circulação da mercadoria, na França, sem que isso pudesse parecer uma ameaça aos interesses econômicos, existia a crença de que era a civilização o que impulsionava uma máquina colonial muitas vezes dispendiosa (Ferro, 1996: 104).

8. De Martonne promove conferências de divulgação da Geografia em rádios e revistas (Defosse, 2001: 194). Ele participa igualmente da "Association française pour l'Avancement des sciences et à l'Académie des sciences" onde empreende uma dupla estratégia de garantir o lugar da geografia no seio das disciplinas científicas e galgar espaço crescente para geógrafos profissionais em relação aos antigos geógrafos "sábios", eruditos e amadores (Defosse, 2001: 196). Nessa linha de atuação, ele cria, em 1920, a "Association de géographes français (AGF)" à imagem das sociedades fundadas na Alemanha e nos Estudos Unidos. De 1920 a 1935, ele é secretário geral da AGF (Defosse, 2001: 196). A publicação da Bibliografia internacional responde identicamente a uma estratégia internacional, aproveitando-se do vácuo deixado pelos alemães após a primeira guerra: "Il s'agit donc de profiter de la mise à l'écart des géographes allemands de la communauté internationale après la guerre pour affirmer la place de l'école de géographie française et cela dans le contexte de l'organisation de l'Union géographique internationale" (Defosse, 2001: 196). De acordo com Dresch, as ações no âmbito interno e externo à França se conjugavam (Dresch, 1973: 545). Similarmente, o congresso internacional de Geografia de Paris ocorrido em 1931 passa por um processo de reorganização que visava a aumentar a intervenção da geografia francesa no processo de direcionamento dessas pesquisas: "c'est une société de géographie locale qui lance les invitations, alors que les congrès ultérieurs sont régis par l'UGI" (Defosse, 2001: 198). Nas palavras de Martonne (1925) “cette autorité s'exerçant désormais d'une façon permanente donne la possibilité d'assurer une unité de méthode et une continuité d'actions précieuse" (citado por Defosse, 2001: 198). Como consequência do congresso, as viagens de De Martonne pelo mundo se intensificam.

9. A distinção de duas gerações de vidalianos, elaborada por Vincent Berdoulay auxiliará na compreensão das dinâmicas institucionais. Segundo Berdoulay, a primeira geração é composta pelos estudantes mais velhos, Dubois (1856-1916), Gallois (1857-1941), Camena d'Alemeida (1865-1943) e Ravenau (1865-1937): «d'une manière générale, ces premiers disciples furent les témoins de l'évolution de la géographie des études historiques ancien style vers les études physiques, humaines et régionales». Esta geração não elaborou teses sob orientação de Vidal mas de Himly, partidário de estudos de História da Geografia (Berdoulay, 2008: 178). A segunda geração é composta por Brunhes (1869-1930), Vallaux (1870-1945), Demangeon (1872-1940), de Martonne (1873-1955), Vacher (1873-1921), Blanchard (1877-1965), Sion (1879-1940) e Sorre (1880-1962). Esta geração recebeu orientação de teses diretamente de Vidal de la Blache, mas seria composta por discípulos ortodoxos e heterodoxos (Berdoulay, 2008: 178).

10. Segundo Demangeon: "Le peuplement rural et l'économie agricole ne cessent pas d'évoluer, no de s'étendre, cédant au besoin constant qu'ont les hommes d'accroître leurs moyens de vivre. Cette pousée s'exerce vers deux directions: elle vise, ou bien à rendre plus intensive la production des terres déjà occupées, ou bien simplement à étendre leurs surface” (Demangeon, 1934: 13).

11. Contudo, isso não está em contraposiçao às considerações de Vidal de la Blache: “Ainsi, au fil des études, la référence est de plus em plus solvente faite aux facteurs macro-économiques. Une notion apparaît par ailleurs, que l'on ne désigne pas encore sous l'expression d'interaction 
spatiale, mais qui renoue avec la conception vidalienne de la relativité de la notion de pays dans le temps et dans l'espace: c'est l'idée que la destinée d'un pays dépend des relations qu'il entretient avec ses voisins" (Ozouf-Mariginer, 2000, p. 84).

\section{RESUMOS}

A partir dos aportes de uma história intelectual com foco sobre as lentidões e permanências, nosso escopo é de demonstrar os motivos pelos quais o geógrafo francês Pierre Monbeig escolhera a Espanha como primeiro objeto de pesquisa de doutoramento. A partir desta trajetória, aparecem os esforços de consolidação de geógrafos formandos na década de 30, no seio da prestigiada geografia francesa, em um contexto de uma atualização metodológica após a consciência da mundialização. Por fim, alargando a mais comum periodização da historiografia da obra de Monbeig, que escolheu como ponto de inflexão a sua ida ao Brasil, em 1935, nosso objetivo é argumentar que um primeiro esboço do modelo das franjas pioneiras, supostamente desenvolvido tardiamente no Brasil, após a sua tese de doutoramento, defendida em 1953, já aparece nos seus estudos do período de 1930 a 1935, anterior, portanto, à sua chegada ao país continental.

From the contributions of an intellectual history focused on the permanencies, we will attempt to demonstrate the reasons by which the French geographer Pierre Monbeig has chosen Spain as his first doctoral research object. Based on this trajectory, methodological and contextual aspects appeared since the consolidation of French geography in the 30, after the conciseness of the mundialization. Finally, extending the periodization commonly used for analysis of Pierre Monbeig studies, whose inflection point occurs face to his trip to Brazil in 1935, we will try to demonstrate that a first draft of the model of the pioneering fringe, supposedly developed late, have already been present in his studies during the period of 1930 to 1935, previous, therefore, to his arrival to the continental country.

A partir de los aportes de una historia intelectual centrado en las permanencias, intentaremos discutir las razones por las cuales el geógrafo francés Pierre Monbeig ha elegido España como su primer objeto de investigación doctoral. En esta trayectoria, aspectos contextuales y metodológicos aparecen desde la consolidación de geografía francesa en el año de 30, después de la conciencia de la mundialización. Por último, al ampliar la periodización comúnmente utilizada para análisis de los estudios de Pierre Monbeig, cuyo punto de inflexión se produce cuando de su viaje a Brasil en 1935, demostraremos que un primer esbozo del modelo de los frentes pioneros, supuestamente desarrollado tarde, ha estado presente en sus estudios durante el período 1930-1935, anterior, por lo tanto, a su llegada al país continental.

À partir des apports d'une histoire intellectuelle centrée sur les permanences, nous essaierons de démontrer les raisons pour lesquelles le géographe français Pierre Monbeig a choisi l'Espagne comme premier objet de recherche du doctorat. À partir de cette trajectoire, ils surgissent les aspects contextuels du moment de consolidation de la géographie française dans les années 30 , notamment à partir de l'effort de mise à jour des géographes après la conscience de la mondialisation. Finalement, élargissant la périodisation habituellement utilisée pour l'analyse des études de Pierre Monbeig, dont le point de basculement se situe au moment de son voyage au Brésil, en 1935, nous essaierons de démontrer qu'une première ébauche du modèle des franges 
pionnières, qui est supposé avoir été développé plus tard, apparaît dans ses études dans la période de 1930 à 1935 . Antérieure, donc, à son arrivée au pays continental.

\section{ÍNDICE}

Índice geográfico: Espanha, Brasil

Mots-clés: Pierre Monbeig, Espagne, franges pionnières

Palavras-chave: Pierre Monbeig, Espanha, franjas pioneiras

Keywords: Pierre Monbeig, Spain, pioneer fringe

Palabras claves: Pierre Monbeig, España, frentes pioneros

Índice cronológico: 1930-1935

\section{AUTOR}

\section{LARISSA ALVES DE LIRA}

Mestre em Geografia Humana pela Universidade de São Paulo. Doutoranda na Universidade de São Paulo e na École des Hautes Études en Sciences Sociales (Paris). Bolsista FAPESP.

lara.lira@gmail.com 